\title{
ATENDER Y RESPONDER
}

\section{Patricio Mena Malet}

Resumen: el presente artículo busca interrogar el atender en su doble acepción, en tanto atención perceptiva y en tanto cuidado. Lo que parece interesante del examen del vínculo entre ambos sentidos es que pone en juego un sujeto que se comprende en relación estricta con la alteridad cuyo modo de ser está determinado por sus respuestas. En este sentido, el examen progresivo que va de la atención perceptiva a la atención en cuanto cuidado aporta recursos importantes para pensar la dimensión responsiva del sí-mismo al alero de los aportes de la fenomenología contemporánea que va de Ricoeur, pasando por Levinas, Marion, Chrétien, Housset y Romano.

Palabras clave: atención, cuidado, encuentro, acontecimiento, respuesta.

Abstract: this paper tries to interrogate the verb "to attend" in its double acceptation, as perceptive attention and as care. What seems interesting in the study of the link between both meanings is that it puts into play a subject who understands himself or herself in strict relationship with an otherness whose way of being is determined by his or her answers. In this sense, the progressive examination that goes from perceptive attention to attention as care brings important resources to think the responsive dimension of the self under the auspices of contemporary phenomenology: Ricoeur, but also Levinas, Marion, Chrétien, Housset and Romano.

Key words: attention, care, encounter, happening, answer.

Licenciado, Magister y Doctor en Filosofía por la Pontificia Universidad Católica de Valparaíso (Chile). Profesor e Investigador en la Universidad Alberto Hurtado, Santiago de Chile. Dirección electrónica: pamenam@uahurtado.cl. Este artículo ha sido redactado en el marco del Proyecto Fondecyt $N^{\circ} 11100061$. El autor agradece a Olivier Abel, Catherine Goldenstein y a los herederos legales de Ricoeur que le han permitido el acceso a los manuscritos de Ricoeur en una estadía realizada el año 2011 en el Fonds Ricoeur en París y en el IMEC de Caen. 
I.

¿Qué significa atender al otro? Tal pregunta nos confronta con la doble acepción que reconocemos en el término atender atestiguado en los vocablos latinos de los éste que deriva: intendere y adtendere ${ }^{1}$. Por un lado, se trata de la atención en cuanto vigilancia y apertura perceptiva al mundo, y por otro de un prestar servicios o cuidados a alguien. Por su parte, el vocablo "cuidado" conserva también esta doble significancia, como por ejemplo cuando solicitamos a alguien que realice un trabajo específico con el mayor cuidado posible. En ese caso, cuidar es prestar el máximo de atención al objeto o actividad por realizar; cuidar es, en dicho ejemplo, atender de tal modo de no descuidar lo por hacer.

Si hay una experiencia en la que queda de manifiesto el doble apuntar del atender es en la de la vigilia en la que nos comprometemos, por ejemplo, por nuestros seres amados: velar un hijo enfermo va de la mano del prodigarle los cuidados necesarios para su recuperación. El velar, el mantenerse alerta y vigilante, es un modo de responder a la solicitud del otro, un modo de cuidarlo. Atender es cuidar y viceversa. De ahí que quisiera proponer las siguientes preguntas: ¿se puede poner atención sin que este mantenerse en vigilia sea, al mismo tiempo, un cuidado sobre algo o alguien?, ¿no requiere el atender, un cuidado propio que lo define en tanto tal? Y por otro lado, ¿cómo podríamos volvernos al cuidado de otra persona, e incluso de una vocación y del mundo, sin la capacidad de abrirnos atencionalmente hacia lo que nos ocupa?

A continuación quisiera examinar los dos sentidos que reconocemos al atender, pero con el fin de avanzar una respuesta a la pregunta ¿qué significa atender a otro? Es claro que esta pregunta contiene ya ambos modos de entender el atender $-\mathrm{y}$ que tal vez no deben ser separados- pues ella puede estar referida tanto a lo que significa poner atención a alguien, como cuando dialogamos con alguien, lo escuchamos o lo vemos, como a la necesaria dilucidación de lo que está implicado en el

${ }^{1}$ Chrétien, Jean-Louis, Pour reprendre et perdre baleine. Dix brèves méditations, Paris, Bayard, 2009, p. 72. 
cuidar a alguien. Ciertamente, ambos sentidos parecen ligados de modo estricto en cuanto el cuidado supone una lucidez que lo alumbre y sostenga en el tiempo, y en tanto la atención de la que somos capaces demanda un tipo de cuidado, de salvaguarda. Al mismo tiempo, la atención, en su doble acepción, nos conmina a pensarla sobre un fondo de alteridad sin el cual no comprenderíamos ni su movimiento intencional ni todo su empeño en recibir y acoger aquello que se nos da para nuestro cuidado. De este modo, la atención es un modo de estar vuelto hacia lo otro, pero al mismo tiempo revela una implicación con la alteridad a partir de la que nos proyectamos, comprometemos y comprendemos como un sí-mismo. Aquello que quisiera destacar con este empeño descriptivo de la atención es precisamente el modo cómo compromete al sujeto en su relación inherente con lo otro de sí, despojándolo, incluso, de sus pretensiones de auto-fundación de y de transparencia. En este sentido, quisiera mostrar en qué sentido atender es responder a la interpelación de la alteridad por la que somos despertados a la tarea de tener que ser, de apropiarnos nuestros posibles en las respuestas que ofrecemos a las exigencias del mundo y del otro: es la experiencia del encuentro, por tanto, aquella que también debe ser interrogada.

A continuación, propongo avanzar desde la atención perceptiva hacia la atención como cuidado y respuesta al otro.

\section{II.}

¿En qué sentido atender algo o a alguien es al mismo tiempo cuidar? Sé muy bien que hay aquí una generalización importante, pues se podría objetar que no atendemos del mismo modo a un útil a la mano que a una persona que precisa de nuestros cuidados, pero, lo que me interesa es describir aquellos momentos constitutivos del atender en tanto cuidar y que, si son tales, son fundantes, por tanto constituyentes de la experiencia misma de atender y del cuidar.

En una primera instancia, se puede afirmar que lo propio de la atención es la posibilidad de la aclaración del objeto percibido; si este último aparece y se dona en sus múltiples escorzos, lo hace desbordando 
la percepción actual, pues "el objeto mismo me guía, según Ricœur, por las solicitaciones de su contexto; sin embargo, yo me oriento entre las apariencias, yo desplazo el acento principal, yo hago girar el objeto o yo desenvuelvo el mismo lado para desplegar los múltiples detalles, o yo lo capto dentro de un conjunto más amplio"?.

¿Cuál es la intencionalidad propia del poner atención? No solo se trata de un estar vuelto hacia las cosas, hacia el mundo y el otro, sino del compromiso que tal movimiento supone: el yo que atiende "está comprometido en la captación del objeto"3 y lo está de un modo prospectivo por lo que el poner atención puede comprenderse según cómo exploramos el mundo a partir del recorrido de nuestra libre mirada capaz de inspeccionar los múltiples aspectos del darse de las cosas y de quedar atrapada en la fascinación de éstas. Hay aquí una pequeña diferencia que es preciso destacar: la fascinación supone una mirada atrapada, tomada por su objeto, mientras que la atención se funda en una mirada gratuita, libre de cambiar de objeto. Mientras que la mirada fascinada es rehén de lo otro, la mirada atenta, adhiriendo al objeto, es, al mismo tiempo, "inherente al sujeto" y a su "libertad de orientación"4.

Poner atención también demanda un dominio de la duración, pues no solo es orientación en el mundo sino también "orientación en el tiempo"5. Anteriormente he indicado que la atención es prospectiva, pero esta última no es sinónimo de anticipación. Si lo propio de la atención es que ésta sea una mirada a partir de la que orientarnos en el mundo, recorrer los objetos en sus diversos escorzos y guardar la libertad de cambiar de objeto, se podría afirmar entonces que la atención es exploración o búsqueda. Atender es buscar, buscar encontrar. Mas, hay búsquedas y búsquedas. Están aquellas en las que queremos hallar algo

${ }^{2}$ Ricœur, Paul, Pbilosophie de la volonté I. Le volontaire et l'involontaire, Paris, Aubier, 1950, p. 147.

3 Ricœur, Paul, "L'attention. Étude phénoménologique de l'attention et de ses connexions philosophiques", Bulletin du Cercle philosophique de l'Ouest, 4, janviermars, 1940, p. 10.

${ }^{4}$ Ibíd.

${ }^{5}$ Ibíd., p. 14. 
preciso, muy específico, por ejemplo un objeto perdido, y hay aquellas otras en las que buscamos sin saber qué. En ambos casos, la búsqueda propende a un encuentro; aunque también hay encuentros que hacemos que no han requerido de nuestra parte ninguna iniciativa en particular ${ }^{6}$, como por ejemplo cuando somos encontrados.

¿Qué hace que una búsqueda sea atenta verdaderamente? Ciertamente no es ni la concentración ni la anticipación. Un atender muy concentrado "arriesga no encontrar sino lo que ya sabíamos o creíamos saber"7. O según Ricœur: "Lo que hace a una búsqueda atenta no es la presencia ni la acción de una idea a priori, es, al contrario, la exploración tan ingenua cómo es posible que está al servicio de la búsqueda: se busca ver, pero se explora para ver. No es la representación ni el deseo que constituyen a la atención, sino la ingenuidad de la mirada"8. Podemos llamar prospectividad al carácter exploratorio del atender que, para ser tal, debe ser ingenuo como la mirada de un infante. De este modo, atender implica un dominio en el tiempo pues requiere de una mirada capaz de "neutralizar su pasado" y liberarse de la duración. La atención se vuelca hacia su objeto sin buscar anticiparlo, precisamente, para captarlo tal como se da. Pero, al mismo tiempo, la inocencia de la atención nos revela el necesario despojamiento del prestigio del sujeto pues su ingenuidad demanda un descuido u olvido de sí a fin de poder volverse verdaderamente hacia lo buscado. ¿No es éste, precisamente, un primer modo de asumir el cuidado por el objeto -tomado este último en un sentido muy amplio? ¿No requiere el cuidado de lo otro y del otro un cierto descuido de sí, y tal vez un olvido de sí, con el fin de volverse atentos a los modos indefinidos de darse aquello que nos demanda y que nos vuelve exploratoriamente en su búsqueda? Tal descuido parece ser el fundamento de la disponibilidad a encontrar y ser encontrado.

${ }^{6}$ Cfr. Chrétien, Jean-Louis, Promesses furtives, Paris, Minuit, 2004, pp. 139-195.

${ }^{7}$ Chrétien, J.-L., Pour reprendre et perdre haleine. Dix brèves méditations, p. 82.

8 Ricœur, Paul, “L'attention. Étude phénoménologique de l'attention et de ses connexions philosophiques", p. 12.

${ }^{9}$ Ibíd., p. 14. 
A la ingenuidad de la mirada hay que adosarle la sorpresa. La verdadera atención no anticipa, sino que explora hasta la sorpresa ${ }^{10}$. Su marcha interrogativa e ingenua la abre a lo no esperado y que no podría ser tal sin cierta inadvertencia del atender. El carácter indagatorio del atender debe contar, en este sentido, con cierta distracción -por ejemplo, la legendaria distracción de Tales de Mileto que cae en un pozo mientras contemplaba el cielo (cf. Platón, Teeteto174 a)- que no solo nos permite desviar la mirada de un sinnúmero de cosas dadas en nuestro horizonte perceptivo sin tener que volvernos conscientes de ellas ${ }^{11}$ así como de los múltiples intereses a los que estamos vueltos, sino que también nos permite concentrarnos en aquello cuyo sentido demanda clarificación, y que puede aportar una verdadera novedad. Atender sin saber qué esperar de lo atendido hace de la atención la clave de la sorpresa y de su propia distracción. En palabras de Chrétien, "el hombre atento es aquel que no se deja fácilmente distraer, porque él mismo está activamente distraído"12. Encontramos aquí un primer vínculo entre atención y cuidado. Pues atender significa al mismo tiempo un abandonarse al "objeto" de la atención para salvaguardarlo: la atención distraída es ya un modo de asumir el cuidado de lo que nos distrae y que supone cierto descuido. No podemos atender y cuidar sin abandono ni descuido. Esta misma estructura podemos hallarla como fundamento de las relaciones cortas que mantenemos con nuestros seres amados y que nos exige no amar a todos, sino tan solo a unos pocos, nuestros allegados. El amor a unos supone la distancia e inadvertencia de los otros; al resto de las personas las respetamos, pero no las amamos como a un hijo.

Así, volvernos a algo, atenderlo, es al mismo tiempo dejar de atender algo más, retirar nuestra mirada o mantener el resto de las cosas en la latencia para que no nos distraiga, precisamente porque ya estamos distraídos, vale decir interesados en algo más. La distracción es también un

${ }^{10}$ Cfr. Marion, Jean-Luc, "El sujeto en última instancia", Revista de Filosofía, $3^{\mathrm{a}}$ época, vol. VI, N 10, 1993, pp. 439-458.

11 Cfr. Romano, Claude, "L'horizon de la phénoménologie". Iris. Annales de philosophie, Vol. 28, 2007, p. 9.

${ }^{12}$ Chrétien, J.-L., Pour reprendre et perdre baleine. Dix brèves méditations, p. 72. 
modo de estar atento, concentrado y enfocado ${ }^{13}$. En cierto respecto, se puede decir que solo lo inaparente, lo inadvertido, permite que atendamos aquello que nuestra mirada recorre. $\mathrm{O}$ para decir esto en un lenguaje más fenomenológico, el atender requiere un campo de inatención o conciencia potencial. Así por un lado, el sujeto se halla desbordado por el objeto que, al mismo tiempo, es destacado o elevado "sobre un fondo que no es estrictamente percibido por él mismo"14. La inadvertencia y distracción son, a su vez, signo de disponibilidad con respecto al objeto atendido. $\mathrm{Y}$ en este sentido, la atención no es tan solo activa, sino activamente receptiva. La mirada ingenua, o "inocente" como la llama Ricœur ${ }^{15}$, se vuelve hacia el objeto, lo explora e interroga para acogerlo en tanto tal. A este movimiento exploratorio de la atención lo podemos llamar "cuidado de la atención", como cuando decimos que es preciso hacer algo con cuidado. En este caso, se trata del cuidado que ponemos en la inspección de la cosa, del objeto, etc. Hay aquí una dimensión temporal importante del cuidado: cuidar requiere ser paciente de la manifestación de lo dado, de lo encontrado, que dándose requiere nuestra constante atención. La inspección del objeto supone la paciencia de su descubrimiento. Más que cumplir una intención vacía, la atención es una exploración cuya espera se sabe expuesta a lo inesperado.

13 Otro sentido de la distracción de la atención puede ser el de reposo, aquel en que nos comprometemos para recobrarnos de la fatiga que produce la concentración requerida para captar un objeto, contemplar una obra de arte, etc. Así también, si se analiza y vincula la decisión con la atención (cfr. Ricoeur, "L'attention. Étude phénoménologique de l'attention et de ses connexions philosophiques, p. 21-24), la distracción puede reenviar a un poder (capacidad) no empleado..., provocado por ejemplo por la pereza.

14 Ricœur, "L'attention. Étude phénoménologique de l'attention et de ses connexions philosophiques", pp. 18-19.

${ }^{15}$ Ricœur, Philosophie de la volonté I. Le volontaire et l'involontaire, p. 147. 
III.

Por su parte, Heráclito afirma: "Si no esperas lo inesperado, no lo encontrarás, pues es penoso y difícil de encontrar" (Diels-Kranz B18). Ciertamente, en la atención hay una espera; todo nuestro propósito se juega en saber cuál es el modo de darse de ésta y qué es lo que resuelta y distraídamente se espera. Pues, incluso cuando se trata de un objeto sensible, la atención no puede ser pensada solo como un movimiento concentrado y voluntario dirigido a una cosa ya claramente identificada. Lo que de un objeto atendible nos importa es, en palabras de MerleauPonty, su no frontalidad, su lateralidad, que nos expone siempre hacia lo invisible de lo visible, aquello que no se muestra sin ocultarse, pero que al mismo tiempo se deja señalar en sus múltiples aspectos y escorzos. La prospectividad está definida por la búsqueda del encuentro de lo invisible, de lo que no puede darse o mostrarse sino repentinamente, de improviso y sin nunca, finalmente, despejarse por completo. De este modo, no es la anticipación de lo atención lo que interesa en este punto, sino la prospección. Apuntamos entonces a lo que se nos dona derribando nuestras esperas; a lo buscado cuando percibimos y atendemos tal o cual cosa. En este sentido, lo interesante es dar cuenta de que lo que funda la atención es precisamente lo que no se puede esperar ni buscar de antemano. La prospección es, por consiguiente, ese movimiento ingenuo, pasible y disponible para la sorpresa, para la novedad que no puede ser acomodada según nuestras esperas. La atención propia del cuidado no se lanza exploratoriamente al mundo sabiendo de antemano lo que se quiere encontrar, sino que, incluso cuando cree conocerlo, está dispuesta a ser transformada de punta a cabo, y con ella el sujeto tal como está vuelto intencionalmente hacia el mundo y sus objetos ${ }^{16}$. Es así que Jean-Louis Chrétien, analizando este tema en el contexto de las tragedias griegas, afirma: "Incluso cuando los dioses proclaman lo que harán, anunciando sus designios, no esperamos eso que se producirá, pues interpretamos sus palabras en el horizonte de nuestras esperas y de nuestros propios deseos"17. Precisamente, la atención se mantiene siempre en una constante

${ }^{16}$ Cfr. Marion, J.-L., "El sujeto en última instancia".

${ }^{17}$ Chrétien, J.-L., L'inoubliable et l'inespéré, Paris, Desclée de Brower, 2000, p. 144. 
falta de preparación, pues no hay modo de anticipar ni de prever lo que es novedoso y sorprendente. Incluso buscando y sabiendo lo que esperamos encontrar, corremos el riesgo de hallar otra cosa a lo que creíamos que encontraríamos. Solo en tanto que somos capaces de esperar, nuestra atención puede ser sorprendida por lo que no podía esperar sin que su advenimiento provocara un estremecimiento en su mundo y sus posibles $^{18}$. La disponibilidad o pasibilidad de la atención nos vuelve resueltamente hacia un sí-mismo fracturado o herido por lo inesperable: ¿Pero no es esta fractura la que, al mismo tiempo, nos permite comprender el cuidado de sí? ¿Qué resulta más inesperable que el símismo que no puede abandonar la tarea de su propia comprensión, de su refiguración a partir de los posibles que se le abren en los múltiples encuentros que hace: con el otro en relación de reciprocidad y mutualidad y con los textos y su mundo refigurable en el acto de lectura?

Cuando decimos fractura, quiebre, herida, decepción, mentamos un encuentro provocado incluso a nuestro pesar, si se trata en efecto de un real encuentro, a saber uno que se ha hallado sin haber previsto de antemano lo que debía encontrarse en el movimiento libre de nuestra atención. Incluso cuando atendemos un objeto, en el sentido más restringido que quisiéramos asignarle y que la historia de la metafísica pueda enseñarnos, es siempre posible un plus, una excedencia, una demasía que puede ser hallada y darse de modo inesperado para fracturar nuestras esperas. Lo relevante, entonces, es aquello a lo que nos abre el atender mismo: el encuentro.

Respecto del encuentro, Claude Romano afirma que: "no esperamos solamente, nos esperan; el que nos espera y nos atrae está para nosotros fuera de alcance y fuera de espera; no somos su medida. El encuentro solo se preludia a sí mismo"19. El caso que cita Romano es más claro pues se trata de un encuentro intersubjetivo. Sin embargo, me parece

18 Romano, C., "Esperar", Franciscanum. Revista de las ciencias del espiritu, N 156, Julio-Diciembre de 2011.

${ }^{19}$ Romano, Claude (1998). L'événement et le monde. Paris, PUF, p. 168. Traducción castellana, El acontecimiento y el mundo (2012), Salamanca, Sígueme, 1998, p. 183. 
que no es indebido hablar también de encuentro cuando nos referimos, por ejemplo, a una vocación. Lo importante es que éste nos es dirigido; cuando hallamos algo, cuando encontramos incluso sin buscar, no solo encontramos algo, sino que nos parece que eso nos ha hallado a nosotros mismos. Es esa interpelación, esa asignación la que define el encuentro. Pero, el encuentro es "improvocable", "insuscitable", pues, como tal, a saber, como acontecimiento, no se reduce a su "efectuación como hecho"20, no disponemos de él y nos expone a lo inexperienciable mismo, a lo invisible de lo atendido, a su demasía que hallamos y nos halla, que estremece nuestro mundo y nuestros posibles. Ciertamente, el encuentro es primero o, si se quiere, es del orden de lo inmemorial, pues no es producto de nuestra iniciativa; para encontrar es preciso haber sido encontrado de alguna u otra forma: se trata, ciertamente, de la lógica propia del acontecimiento en su sentido contecedero o acontecial ${ }^{21}$, es decir, adviniente y sorprendente.

De este modo, no hay encuentro que no subjetivice, que no singularice a quien hace su experiencia como en sobresalto o paralizado por la sorpresa del acontecimiento. El encuentro supone que el sí-mismo sea capaz de afección, de auto y hetero-afección, por lo que el arribo de la novedad pone en juego la muidad (miénneté) del sujeto. El encuentro se deja notificar, aunque de modo a posteriori, tras su arribo y su afectación que alcanza al sujeto y sus posibles. Mas, lo que me interesa destacar sobremanera es aquella responsabilidad sui generis a la que somos vueltos tras el encuentro, por ejemplo el que hacemos como padres de nuestros hijos. En efecto, éste es la ocasión de la responsabilidad, aquella que no tiene su origen, de modo estricto, en mi iniciativa, sino que me es dada o

\section{${ }^{20}$ Ibíd.}

${ }^{21}$ Asumimos, desde ya, la distinción que hace Claude Romano entre "contecedero" o "acontecial" (événmential) y "acontecedero" o "aconteciario" (événementie), para referirse en el primer caso al acontecimiento en sentido fuerte, radical, como aquel hecho intramundano (acontecedero) que no se restringe a tal, sino que es impredecible, sorprendente, singularizante, etc. Todas modalidades que lo definen como el fenómeno por excelencia. 
es portada en el acontecimiento que me arriba. En este sentido, la ipseidad siendo pasible es también responsiva, pues recibir un acontecimiento es también ser vuelto hacia una responsabilidad que no puede dejar de ser asumida, inclusive si decidimos no responder o comportarnos irresponsablemente ante lo hallado, lo que no serían sino modos debilitados de responsabilidad. Con el encuentro nos recibimos asumiendo el cuidado de aquello que hallamos y que nos encontró. Uno de los casos más notables de ser analizados es, a mi parecer, el de la filiación. En efecto, incluso cuando una pareja busca incansablemente tener un hijo nada nos permite afirmar que ese hijo buscado, anhelado y deseado, nazca cumpliendo las esperas de sus padres; más bien, afirmaremos que su nacimiento, siendo un acontecimiento en el sentido contecedero, llega siempre de manera inesperable y sorprendente al punto de romper el prestigio de nuestras esperas. Pero, por otro lado, tampoco es del todo cierto que seamos solo nosotros, los padres, quienes hallamos a nuestro hijo al momento de nacer, pues también somos encontrados por él, y tal encuentro nos vuelve responsables de modo singular, inapelable, al punto que su advenimiento nos permite, a su vez, encontrarnos a nosotros mismos como padres; es decir como capaces de responder a su llamado. Volverse padre es encontrar y ser encontrado, es dejarse demandar por una nueva responsabilidad tan original como impensable antes de su asunción.

De este modo, el atender es un modo de ser estructural del sujeto que se recibe en el encuentro de aquello que dándosenos nos remite a la experiencia de recibirnos en una responsabilidad que se asume aceptando el descentramiento del envío que promueve el paso del "yo" en nominativo al acusativo del "heme aquí". Este encuentro se hace de modo irreversible; encontrando, ya no podemos sustraernos de su experiencia, de su donación y de la manera cómo nos recibimos en el envío al que nos lanza. El atender como cuidado es a lo que nos vuelve esta responsabilidad sui generis, es el modo como respondemos haciéndonos cargo y asumiendo la guarda de lo que se da según el modo del acontecimiento. La irreversibilidad está marcada por el hecho de que, encontrando, no podemos dejar de responder y de volvernos responsables. Cuando decidimos no responder y no asumir el cuidado, por 
ejemplo de un hijo, incluso en esos casos, estamos respondiendo y asumiendo una responsabilidad aunque en su modo más débil como es el de la irresponsabilidad.

\section{IV.}

Con toda seguridad, una cosa, un objeto, no se presenta o se dona del mismo modo que una persona a menos que, a esta última, la atendamos como un objeto de nuestra percepción sin la pretensión de encontrarnos con la "persona", con el otro. Pues, es propio de la intencionalidad, y la atención perceptiva es sin ninguna duda intencional, estar vuelta hacia objetos y meramente objetos; de ningún modo nos da acceso al otro en su alteridad. Es así que Jean-Luc Marion puede afirmar que "la intencionalidad no abre más que a la objetividad de los objetos intencionales, nunca directamente a otro sujeto"22. Y en Figures de phénoménologie afirma:

Ahora bien, ocurre como si la atención inquieta con respecto a la cuestión de la intersubjetividad valiera como el síntoma de una imposibilidad persistente no solo de responder a ella sino simplemente de acceder a ella. Pues, en relación con la intersubjetividad, la verdadera aporía, al menos (o sobre todo) desde Descartes, no se refiere tanto a la inaccesibilidad del otro, como a su accesibilidad demasiado fácil. No hacemos alusión a la facilidad de mi acceso al otro como un objeto entre otros, constituido por mi juicio al mismo título que un pedazo de cera: aquí el otro no tiene más que el rango de un objeto y se encuentra desde el comienzo despojado de su alteridad, puesto que el objeto pertenece a aquel que lo constituye, el ego. Apuntamos aquí al acceso al otro no como objeto, sino como otro ego (si se quiere un sujeto), literalmente como otro sí-mismo ${ }^{23}$.

${ }^{22}$ Marion, J.-L., Prolégomènes à la charité, Paris, Éditions de la Différence, 2007, p. 102.

${ }^{23}$ Marion, J.-L., Figures de phénoménologie. Husserl, Heidegger, Levinas, Henry, Derrida, Paris, Vrin, 2012, pp. 152-153. 
La atención perceptiva nos da acceso a objetos intencionales pero no nos abre al otro, a su rostro, su expresión, su palabra, su conminación. Y es precisamente, el "objeto" de nuestra atención el que da cuenta de la metamorfosis del atender. El otro en su alteridad se dona diferentemente a un objeto intencional: a juicio de Levinas, habría que decir incluso que se sustrae de toda fenomenalidad; el rostro se da sin darse nunca como fenómeno. "El rostro, afirma Levinas, está presente en su negación a ser contenido. En este sentido no podría ser comprendido, es decir, englobado. Ni visto, ni tocado, porque en la sensación visual o táctil, la identidad del yo envuelve la alteridad del objeto que precisamente llega a ser contenido"24. Pero, entonces, ¿qué significa encontrar al otro y ser encontrado por él? Para responder a esta pregunta, y aquellas que nacen lateralmente a partir de aquí, quisiera abrir el diálogo con Marion y Chrétien.

A juicio de pensadores como Levinas y Marion el otro no es objeto, siendo lo propio de los objetos el ser visibles. "¿Por qué el otro no tendría que ser visto -se pregunta Marion-? Porque nada puede verse que no deba primero mentarse y nada puede mentarse sino como un objetivo de antemano sometido a la mirada que construye su objeto"25. Es decir, el objeto es visible porque el mentar que lo intenciona suscita lo visible; pero el otro en tanto otro es irreductible al mentar, al intencionar; él mismo intenciona sin nunca volverse visible. En un sentido similar Michel Henry afirma que "el otro nunca me es dado en su existencia originaria, en su secreto, es siempre para mí un secreto, y eso no porque sea libre, en virtud de un carácter, sino por una razón esencial que es que el ser originario del ego y por tanto del alter ego no se produce, no se exbibe nunca en el mundo y no es susceptible de ser captado por mi"'26. De este modo, el otro no se da sino como invisible y resistente a la mirada que lo enfoca, lo engloba y lo encierra:

${ }^{24}$ Levinas, Emmanuel, Totalidad e infinito. Ensayo sobre la exterioridad, Salamanca, Sígueme, 1977, p. 207.

${ }^{25}$ Marion, J.-L., Prolégomènes à la charité, p. 103.

${ }^{26}$ Henry, Michel (2011). "La communication des consciences et les relations avec autrui. Cours d'Aix-en-Provence (1953-1954)". Revue internationale Michel Henry, $\mathrm{N}^{\circ}$ 2, p. 156. 
mirar verdaderamente al otro es más que ver su cara, sus ojos, su silueta; al otro se le enfrenta, y nuestra mirada objetivante no lo capta; se le enfrenta encarándolo en su mirada como la "viva refutación de la objetividad"27. A fondo perdido, la mirada del otro sostiene la mía pero como un invisible que me da a ver sin mostrarse él mismo. "Mirar al otro como tal, afirma Marion, mis ojos en lo negro de los suyos, no implica encontrar otro objeto, sino que experienciar lo otro del objeto. Mi mirada, por primera vez, ve una mirada invisible que la ve. Yo no accedo al otro viendo más, mejor o de otro modo, sino renunciando a dominar lo visible para ver objetos, por tanto dejándome enfrentar por una mirada que me ve sin que yo la vea -mirada que, invisiblemente, silenciosamente me engulle y me sumerge, sépalo o no, quiéralo o no" 28 . De este modo, siendo que la intencionalidad mienta objetos, el otro en tanto otro, precisamente a causa de la intencionalidad, no puede sino sustraerse a nuestra mirada pues ésta solo es apta para captar aquello que puede englobar o mentar: un objeto. De algún modo, es el otro quien me alcanza antes que yo mismo lo capte, si hay algo como un acceso al otro no conforme al modelo de la mirada, de la luz, de la intencionalidad, sino de la escucha: pero, el otro no se da sino como lo que llama y conmina, lo que significa que su presencia se dona en mí volviendo al yo en acusativo, lo que supone también que el otro reduce mi conciencia destituyéndola de intencionalidad ${ }^{29}$. El otro me encuentra "en una exterioridad irreductible" 30 , y encontrándome me hallo vuelto hacia él, que me mienta o intenciona, sin nunca poder, yo mismo, reducirlo a los objetos que yo intenciono: el otro adviene en o como una exterioridad total que transforma al yo nominativo en acusativo.

Si el otro no sucumbe a mi mirada, si la atención perceptiva no puede darme para mi ocupación y preocupación sino objetos, entonces ¿cómo atender al otro en tanto otro?

${ }_{27}$ Marion, J.-L., Prolégomènes à la charité, p. 104.

28 Ibíd., p. 105.

${ }^{29}$ Ibíd., p. 106.

${ }^{30}$ Ibíd., p. 107. 
La atención que ponemos a un hijo, a un amigo, a un prójimo demanda una atención no orientada de antemano. Podría afirmarse que del amigo o un hijo no esperamos nada más que su presencia y sus manifestaciones. Por el contrario, afirma Chrétien, "solo el manipulador y el seductor tienen desde el comienzo una atención orientada"31, pues saben lo que buscan. La atención al otro, al ser amado, más bien está abierta e inquieta por su presencia sin poder acotarla y viéndose el sujeto desbordado por su modo de darse; y en este sentido, dicho atender no tiene como fundamento el querer o la voluntad, sino la disponibilidad. La espera del atender radica en "la espera de la manifestación de eso a lo que somos atentos, y que le deja, sin precipitarnos, su tiempo y su modo de despliegue" 32 . En última instancia, la atención requiere de la paciencia del tiempo de manifestación de los fenómenos. Mas, ¿esto le agrega alguna nota distintiva respecto de la atención a un objeto dado en la percepción sensible? No, pero, tal vez, nos permite hundir el atender en la disponibilidad y el compromiso. Siguiendo a Chrétien, podríamos decir que la atención al otro nos permite entender de mejor manera en qué sentido ésta es sin prevención alguna, sin ningún tipo de anticipación.

Atención sin prevención significa que el amigo es esperado, que nuestra atención le es desde el comienzo abierta sin que tenga que requerir ni forzarla, sin por tanto que hayamos decidido lo que se manifestaría, ni en qué, ni por qué (y todavía menos lo que debería manifestarse). Pues el peligro de una demasía de solicitud es que el otro termine por sentirse en la posición de un solicitante y de un mendigante de atención. La atención libre es aquella que deja libre, y por consiguiente deja devenir libre ${ }^{33}$.

${ }^{31}$ Chrétien, Jean-Louis, Pour reprendre et perdre haleine. Dix brèves méditations, p. 83. 32 Ibíd., p. 84.

33 Ibíd., p. 85. 
Este análisis nos permite subrayar un sentido más fuerte de atención: el de vigilia ${ }^{34}$, el estar en vela por un otro. Ciertamente, la paternidad puede ser ejemplar en este caso en la medida que nos permite esclarecer lo que quisiera llamar el "abandono de la vigilia" y que se deja entender sobre todo en el caso de las relaciones $\operatorname{cortas}^{35}$-a saber las que mantenemos con nuestros prójimos, nuestros hijos, amigos, seres queridos-. ¿Cómo podemos entender el estar en vela? $\mathrm{Al}$ respecto quisiera citar in extenso un texto Jean-Yves Lacoste por lo relevante que me parece para el tema:

Sólo el ángel ignora el sueño -el arameo le da el nombre de 'vigía'-; nosotros, en cambio, no existimos bajo el modo perpetuo de la vigilia de la conciencia. Y el sueño, como ser-menos y como figura del ser-menos, de la no-existencia, nos enseña que no ejercemos sobre nosotros mismos ninguna relación de dominación: la 'vida', por el contrario, ejerce ahí un poder sobre la 'existencia'. ¿Qué hace, entonces, el hombre que no duerme y que gana tiempo para la vigilia? En la experiencia más común (¿quién no ha permanecido jamás en vela?) hay mucho en juego: se trata, para seguir empleando el mismo léxico, de una protesta de la 'existencia' contra la 'vida', de una protesta que se hace con la victoria. El animal es capaz de insomnio o simplemente de permanecer despierto porque tiene hambre o miedo ( $y$, ciertamente, yo puedo permanecer en vela por las mismas razones). Pero no tendría ningún sentido decir que es capaz de velar: los límites de la vigilia no son los de una obligación, se trata de algo que debe ser querido (...). Con todo, lo que está verdaderamente en juego sigue allí y rehusarse a dormir esconde una afirmación poderosa. Podemos oponernos a las exigencias de la 'vida' para 'existir' un poco más. El tiempo de la vigilia es verdaderamente nuestro tiempo, aquel que ganamos sobre la no-libertad y la no-conciencia, sobre las puras necesidades

34 Para una caracterización de la vigilia, como un estar despierto, en contraposición al sueño, cfr. Strauss, Erwin (2000), Du sens des sens. Contribution à l'étude des fondements de la psychologie, Grenoble, Million, 2000, pp. 319-337.

35 Cfr. Ricœur, Paul, Histoire et vérité, Paris, Seuil, 1967, pp. 113-127, y Dosse, François (2012), Paul Riccuur. Un philosophe dans son siècle, Paris, Armand Colin, 2012, pp. 159-161. 
biológicas (...). El acto de velar nos aparece, así, como pura posición de sí, como compendio de una afirmación de nuestra libertad ${ }^{36}$.

El texto recién citado me permite comprometer el análisis por la siguiente vía: si atendemos al final del fragmento, se podría objetar la pertinencia de esta referencia para nuestro propósito, donde lo que buscamos interrogar es ¿qué significa atender al otro? Pues, si velar indica una posición de sí y es signo de nuestra libertad, entonces, podría preguntarse ¿qué lugar tiene la otra persona en este análisis? Pero, tal objeción tiene su fundamento en un mal entendido; pues, que el velar remita a un yo que se plantea en su acto no desmerece en nada el hecho del motivo por el cual nos mantenemos en vela. Ciertamente, solo un sujeto capaz de estarlo, y de considerarse con los poderes para ello, puede velar, y en este sentido el acto supone una cierta reflexividad que no hallábamos en la atención, pues todo el análisis consistía en descubrir el atender en su despliegue mismo. Pero, en el velar, siendo un modo de atender al menos en los casos de las relaciones cortas con el prójimo, hay una resolución, una decisión que ha zanjado el carácter exploratorio de la atención. En este sentido, me parece que el mantenerse en vela no busca interrogar el trasfondo para esclarecer el objeto atendido. Si el velar, según Lacoste, es una protesta a la vida, vale decir una resolución por la existencia, eso no puede significar otra cosa que velamos porque nos reconocemos responsables de... y ante... Así, por una parte, quien se mantiene en vela es quien está resuelto a comprenderse en sus capacidades, en sus poderes, quien busca resolverse en cierta autonomía con respecto al impulso vital; pero, por otra parte, este remitir al "yo puedo" está orientado como respuesta a una solicitud o una conminación: la de un hijo, por ejemplo.

Pero el velar puede decirse de muchos modos: nos mantenemos despiertos porque requerimos estudiar, porque queremos rezar o salir de juerga; también porque nos sentimos interpelados por otro. Se podría

${ }^{36}$ Lacoste, Jean-Yves, Experiencia y absoluto, Salamanca, Sígueme, p. 109. 
afirmar que, en este caso al menos, la vigilia hace de nuestra existencia un desvelo constante, pues tal vez nunca se deja de temer por un hijo. La vigilia no es sino la preocupación, el cuidado y la asunción de una responsabilidad que nos desborda. La vigilia no es una mirada fascinada, sino preocupada.

La vigilia que vuelve nuestra existencia una noche desvelada no podría ni atender ni tender al otro -vigilia no implica de ningún modo un acceso al otro en tanto otro-, sin un abandono de sí y al otro. De los múltiples sentidos que puede tomar el abandono, me interesa destacar el de ofrenda: en la vigilia del otro, para y por el otro, nos abandonamos a él; lo que no significa, necesariamente, que nos olvidemos de nosotros mismos, sino que asumimos la responsabilidad a la que el otro, precisamente en su advenimiento, me ha vuelto. Pero también este abandono puede significar el renunciamiento a querer volver al otro un objeto, incluso un sujeto si se quiere. El ejemplo de la filiación me parece en este sentido ejemplar. El hijo no es primeramente la perpetuación de una herencia, de un linaje, sino también y tal vez en primer lugar, el nombre de una novedad no enfrentable. Pero, al mismo tiempo, la filiación nos obliga a reconocer una precedencia inmemorial que derriba las pretensiones de autofundación y de transparencia. Nacidos hijos, somos herederos y la expresión de lo nuevo. En la vigilia, finalmente, velamos al hijo para que pueda abandonarnos y abocarse a lo posible, a sus posibles. El abandono de la vigilia no mienta, no intenciona al hijo, sino que responde a su conminación para volverlo hacia sus posibles. El velar busca, primeramente, dejar ir. Velamos con temor, pero con la esperanza de que nuestros hijos puedan partir.

La vigilia paterna se nutre de la paciencia, pues finalmente velar a un hijo es no poder nada sobre él, sino esperarlo, esperar que sea. Me apaciento a mí mismo conminado por el otro.

Quisiera terminar este parágrafo recordando la siguiente reflexión de Ricœur: "Cuando afirmo que un ser me es dado como presencia o como ser (...) eso significa que no puedo tratarlo como si estuviera simplemente planteado ante mí, entre él y yo se anuda una relación que en un cierto sentido desborda la conciencia que puedo tomar de él; no es 
solamente ante mí, es también en mí"37. Estas palabras, que recuerdan a Marcel, permiten poner el último acento. Mientras que en la atención a las cosas, a los objetos, estos están ante mí, en la vigilia el otro no está dado de ese modo, sino en mí. Velamos al otro, por ejemplo en el sentido de asumir sus cuidados, precisamente porque nos concierne, porque estamos resueltamente implicados en él.

V.

Llegados a este punto es necesario profundizar en la dimensión responsiva del atender. Según Ricœur, "el otro es el hombre de la respuesta. Y en la respuesta es integralmente segunda persona" 38 . Cuando el autor de "Travail et parole" -texto publicado originalmente en $1953 \mathrm{al}$ interior de un debate promovido en Esprit tras la muerte, en 1950, de E. Mounier- subraya lo que hoy podemos llamar la responsividad del ser humano, lo hace en el marco de un verdadero elogio de la dimensión pragmática del lenguaje ${ }^{39}$. Ricœur distingue entre la palabra imperativa, dubitativa, indicativa y la palabra lírica. No me detendré en los análisis específicos de tal clasificación pues me importa más bien esclarecer en qué sentido el hombre, el otro, es aquel de las respuestas. En primer lugar, que el otro sea el de las respuestas puede significar muchas cosas, por ejemplo: a) que a él le corresponde responder y no a mí, como cuando al preguntársenos algo en vez de asumir nosotros la iniciativa de la respuesta indicamos al vecino para que la tome. Se trata, en este caso, de una suerte de renuncia a tener que vérselas no solo con la palabra que se nos ofrece sino también con tener que enredarnos y comprometernos con el destino mismo de la respuesta. b) Pero, por otro lado, que el otro sea el de las respuestas puede significar que lo reconozco como interlocutor en un diálogo posible. No se trata aquí de renunciar a tomar la iniciativa de ir tras la respuesta, sino de reconocer que no daremos con ella sino con el

37 Ricœur, P., “L'attention. Étude phénoménologique de l'attention et de ses connexions philosophiques", p. 28.

${ }^{38}$ Ricœur, P., Histoire et vérité, p. 248.

${ }^{39}$ Cfr. Dosse, F., Paul Ricaur. Un philosophe dans son siècle, pp. 161-164. 
otro. c) Mas, también puede significar que es por el otro que hallaremos la respuesta, no necesariamente porque sea él quien responda y no nosotros, sino porque es él la instancia a partir de la que se abre la necesidad de responder. Porque hay otro, hay "negación", hay "no", es decir, hay interrupción del discurso natural e ingenuo en el que nos dejamos llevar sin cuestionamiento. La presencia del otro es, en este sentido, una conminación a abrirnos a la interrogación y a la duda. El otro es el de las respuestas porque, al mismo tiempo, abre el espacio de lo posible refutando el "prestigio del hecho" y la naturalidad del "hay" - "hay" cosas, hay naturaleza; hay la historia, la ley del trabajo, hay el poder de aquellos que mandan" 40 . En suma, el otro es el de las respuestas porque conmina, apela, y descentra al sujeto en sus pretensiones comprensoras y significantes; en un lenguaje más patético podría afirmarse que el otro es la ocasión de las respuestas y de que avancemos hacia ellas, no solo porque duda -siendo esa duda dirigida también sobre nosotros y los modos como nos orientamos en el mundo-, sino también porque nos reconocemos asechados por la sospecha que dirige constantemente sobre nuestra palabra y acción o nuestra palabra actuante ${ }^{41}$. No se trata solamente de la duda, sino también de la sospecha inquisidora y desconfiada. En este sentido, la palabra dubitativa, y habría que agregar la palabra que sospecha, abre hacia lo posible apelando a la responsabilidad del sujeto por el sentido de sí, del mundo y del otro. Pero, al mismo tiempo, rompiendo con la ingenuidad, con el naturalismo - la palabra dubitativa, podría afirmarse, actúa ya como una epojé fenomenológica que pone entre paréntesis el sentido del mundo-, también plantea la instancia de la crítica; pues, finalmente, que el otro sea el de las respuestas, que sea su ocasión, significa que ni él ni yo las poseemos. Desposeídos de las respuestas, la conminación nos vuelve a su búsqueda en las cosas mismas, en las palabras que significan y anticipan todo gesto, engloban la praxis y nos vuelven habitantes de un sentido que es preciso descubrir.

${ }^{40}$ Riccur, P., Histoire et vérité, p. 248.

41 Ricœur, P., "La Parole, instauratrice de liberté", Cabiers universitaires catholiques, 1966, No 10, juillet, 166, pp. 493-507. 
No hay respuesta última ni definitiva, no hay un detentor privilegiado de éstas, pero sí hay una conminación a responder o, si se prefiere, a corresponder con el llamado de las cosas, del mundo y del otro ${ }^{42}$. Esta tesis es muy clara en Amor y justicia, particularmente en las dos conferencias de las Gifford Lectures que Ricœur excluye de la composición final de Soi-même comme un autre.

Siendo la palabra dubitativa la que nos abre a la aventura de responder, es ésta misma la que nos impide dejar de responder, pues mantiene abierta la posibilidad de la contestación. La palabra dubitativa también es apelante y nos vuelve a la tarea tanto de abrir lo posible como de mantenerlo abierto por vía de la crítica, la duda y la sospecha. Pero, he aquí una cuestión a mi parecer fundamental: ¿qué implica esta vacilación de la palabra que se resuelve en la exigencia de interrogar más para responder mejor?, ¿no hay allí, así como en el caso del encuentro analizado anteriormente, una asignación a la responsabilidad que se traduce en asumir la guardia, el cuidado del sentido a través de la interrogación e inspección constantes como de la crítica que evita la clausura y la totalización del sentido buscado? Esto es lo que propongo llamar el "cuidado de la respuesta". La palabra dubitativa, que es también la ocasión de la pausa y por tanto de la distancia tomada ante la atención fascinada, asume el cuidado del sentido dejándose sorprender por su encuentro a la vez que se sobrepone a su sorpresa y afectación tomando el "cuidado" de responder, es decir de interrogar para responder o de cuestionar en tanto que éste ya es una respuesta al sentido dado "ya ahî" de modo interpelante. De esta manera, la palabra dubitativa es la ocasión y lucidez del cuidado así como la exigencia de asumir, vía la interrogación y contestación, el cuidado de la respuesta.

Hablar de lucidez no solo supone la crítica y distancia que aporta la palabra dubitativa previniéndonos de la ingenuidad de nuestro trato con el

42 Mena, Patricio, "Vocación y conflicto. Perspectivas a partir de la hermenéutica bíblica de Paul Ricœur", en Revista de Taller de letras, NE2, PUC, Santiago de Chile, 2012, pp. 73-82. 
mundo y volviéndonos a la responsabilidad del cuidado; también implica una confianza fundamental en el poder significante y exploratorio de la palabra. De algún modo, la palabra dubitativa e interpelante se sostiene en su poder afirmativo: antes de decir "no", para negar y para detener el discurrir precipitado y anticipatorio del decir -vale decir, ingenuo-, la palabra ha dicho primero "sí", pues reconoce en su finitud la oportunidad de abrirse indefinidamente al sentido. De esta manera, el fondo último de la palabra son el consentimiento y la confianza ${ }^{43}$, la finitud de la palabra y su vehemencia; he aquí la condición de posibilidad de la apertura a la que nos dispone la duda. En un sentido semejante -aunque refiriéndose en este contexto al pintor-, Maurice Merleau-Ponty afirma en La prose $d u$ monde que: "el pintor es un hombre de trabajo que encuentra cada mañana en la figura de las cosas la misma interrogación, el mismo llamado al que nunca ha dejado de responder. A sus ojos, su obra nunca está hecha, está siempre en curso" 44 . Es claro que lo que está en juego es la capacidad del sujeto, del sí-mismo, de ser interpelado por las cosas, el mundo y los otros, y de ser puesto en cuestión por lo requirente de tal modo que nuestras respuestas no agotan la llamada que se nos dirige. Así, como en el caso del pintor de Merleau-Ponty, nunca terminamos de responder a las múltiples apelaciones que nos demandan; de responder asintiendo, interrogando, dudando y sospechando, pero también haciendo obra, confiando en el poder de significancia de la palabra y de apertura de un campo de sentido inédito en tanto que la palabra apelante nos vuelve hacia lo posible. Entre Merleau-Ponty y Ricœur, salvando todas las diferencias que los separan, hay por tanto una confluencia: ambos confían en el poder de "significar más allá de la simple existencia de hecho, de inaugurar un sentido" y refigurarlo.

El trabajo incesante de la respuesta, su "cuidado" -como cuando pedimos que algo se haga con cuidado, laboriosamente-, remite también a

43 Mena, Patricio (2011). "Homo capax", Revista Teología y vida, Vol. LII, 2011, N 4, pp. 625-645.

${ }^{44}$ Merleau-Ponty, Maurice, La prose du monde, en CEuvres, Paris, Gallimard, 2010, p. 1486. 
un sujeto que es segundo respecto a la interpelación ${ }^{45}$. El retomar incesantemente la llamada de las cosas, del mundo y del otro para abocarse indefinidamente a su respuesta indica, al menos, lo siguiente: en primer lugar, que la llamada no se deja reducir a nuestras intenciones ni a los modos cómo la mentamos porque no se muestra sino en las respuestas que le ofrecemos ${ }^{46}$ no quedando exenta - todo lo contrario- de la palabra dubitativa, de la crítica y la sospecha; en segundo lugar, las respuestas que ofrecemos, como las del padre al hijo o del pintor a las figuras de las cosas, son más bien correspondencias; no se dejan clausurar en ningún modelo adecuado, pues su intención primera no es la de resolver un problema planteado por una pregunta que oficiase de llamada, sino de responder a los desafíos que esta última le ofrece para recibirse en la correspondencia al riesgo, incluso, de la contestación. De este modo, el cuidado de la respuesta no es signo de su fracaso constante sino del esfuerzo de dejar escuchar el llamado y su envío en las respuestas por las que retomamos el mundo y su sentido cada mañana de un modo nuevo.

VI.

Tras estas consideraciones sobre la apelación habría que preguntarse por el sentido que tiene la "obediencia" a la palabra que conmina, a la presencia del otro, de la persona que nos llama en su rostro, en su grito - por ejemplo en el caso de un hijo que con su llanto nos vuelve hacia nuestra responsabilidad como padres-. Pero, sobre todo, quisiera poner el acento en el carácter acontecial o contecedero de la palabra o, en términos propios de la teología de Ebeling retomada por Ricœur, en el "acontecimiento de la palabra". Esto nos permite situarnos aún en los límites y posibilidades de nuestra reflexión actual a partir de la que hemos intentado pensar el cuidado a la luz del encuentro como acontecimiento. ¿Qué implicancias tiene pensar la palabra como acontecimiento? Para responder, un breve texto de Ricœur: "Pensemos en

\footnotetext{
${ }^{45}$ Cfr. Marion, J. -L., "El sujeto en última instancia".

${ }^{46}$ Cfr. Chrétien, J.-L., L’appel et la réponse. Paris: Minuit, 1992.
} 
nuestra pretensión de ser el amo, de ser aquel que dice 'la verdad' y que dispone de ella como disponemos de las cosas y de los objetos. Cuando yo recibo una palabra, una nueva situación es creada de la que yo no soy el amo, Mi dominio es puesto en cuestión por este acontecimiento de descentramiento; yo no estoy más en el centro; otra palabra. Entonces, ¿qué significa aquí obedecer, a partir de este no-dominio del origen de la palabra? Significa primero y esencialmente escuchar"47. Y un año antes escribía: "En el acontecimiento de palabra no dispongo de nada. No me impongo. Estoy en una situación de no-dominio absoluto, en una situación donde todo dominio está puesto en cuestión"48. Lo que Ricœur viene de señalar, el carácter descentrado del sujeto por la palabra que acontece, que viene e irrumpe, nos instala de lleno en la crítica del sujeto desencarnado: el sujeto capaz de palabra, de recibirla y de callarse para escucharla, no se comprende como su origen, sino en relación con el origen inmemorial del acontecimiento de palabra; se halla sumido en una situación que demanda el esclarecimiento del sentido y su cristalización. De Thévenaz, Ricœur comprende que "un acontecimiento no es solo un corte en el tiempo, es también una cristalización de sentido. No puedo hablar de un acontecimiento si es solamente una ruptura. Yo hablo de él en la medida en que, a partir de este acontecimiento, puedo reunir significaciones en suspenso"49. Ciertamente, Ricœur anticipa las reflexiones que elaborará en Soi-même comme un autre sobre la unidad de la historia de una vida que solo se atestigua en nuestra capacidad de componer historias, de realizar la síntesis de lo heterogéneo, es decir, de los acontecimientos que hacen época y estremecen nuestra identidad. La cuestión para Ricœur no puede centrarse solo en el momento páthico de la acogida del acontecimiento, sino que es preciso atender a los modos cómo el sujeto comprende el sentido articulándolo en las múltiples narraciones en las que se compromete como autor y personaje.

47 Ricœur, P., “Autonomie et obéissance”, Cabier d'Orgemont, $\mathrm{N}^{\circ}$ 59, janvierfévrier, 1967, p. 11.

48 Ricœur, P., "La Parole, instauratrice de liberté", Cabiers universitaires catholiques, 1966, No 10 , julliet, p. 499.

${ }^{49}$ Ibíd., p. 504. 
Por otro lado, "el acontecimiento es tal en la medida que abre perspectivas, que hace comenzar series nuevas de otros acontecimientos ligados entre ellos $\mathrm{y}$ capaces de ser comprendidos en su encadenamiento" 50 . El acontecimiento mismo porta un sentido y su propia hermenéutica, en términos propios de la hermenéutica acontecial de Claude Romano, podríamos decir que éste porta su propio contexto, es por tanto novedoso y sorprendente. $Y$ sin embargo, si el acontecimiento nos abre a nuevos posibles, a significaciones novedosas que rearticulan nuestro ser en el mundo y nuestro ser con, al mismo tiempo no es posible captar su innovación si no es a través del acontecimiento simbólico, vale decir, de los recursos simbólicos, culturales de los que disponemos. Si el acontecimiento nos abre a nuevas perspectivas éstas no dejan de ser siempre un modo encarnado y finito de entrar en relación con el sentido.

Ante la palabra, el hombre se comprende a sí mismo como un sujeto capaz de acontecimiento; esto es, capaz de recibirlos, de ser transformado por ellos, pero también de comprenderlos, de esclarecer y descifrar su sentido "con todos los recursos de nuestra cultura"51. Así, la palabra como acontecimiento porta un sentido que demanda nuestra "obediencia" y "nuestra libre inteligencia" 52 . Es necesario detenernos un instante en esta dupla pues nos instala en los fundamentos ontológicos del cuidado. Cuando Ricœur habla de obediencia ciertamente no se sitúa en el plano moral, sino ontológico. La obediencia a la palabra que nos toca, que nos encuentra, no se deja confundir con la obediencia a la autoridad o algún mandato cualquiera. Lo que manda o requiere nuestra obediencia es la palabra que nos arriba. No es la voluntad la que está en juego, pues la obediencia es "un modo de ser, una manera de existir" 53 , una estructura del ser del sí-mismo. ¿En qué consiste este modo de ser? En primer lugar la obediencia es un modo de ser responsivo del sí-mismo, pues depende de su capacidad de auto y hetero-afección, o en otros términos, de hacer el encuentro de la alteridad que la conmina. Aquel capaz de obedecer solo

\footnotetext{
50 Ibíd.

51 Ibíd.

52 Ibíd., p. 503.

${ }^{53}$ Ibíd., p. 499.
} 
puede ser tal porque está en relación con lo otro, porque puede ser afectado en el encuentro y puede comprender la situación en la que está imbricado articulando su sentido. Si se quiere, la obediencia es un modo activo de acoger las exigencias y los envíos que porta la palabra. En este sentido, la obediencia va de la par de la autonomía en tanto "aptitud para interpretar nuestra vida de cultura" 54 a la luz de lo que nos interpela: el mundo y los otros. ¿La obediencia no es otro modo de decir el cuidado de la respuesta en cuanto aquella escucha, hace silencio para dejar manifestarse a la palabra sin renunciar a la duda, a la sospecha, a la crítica? La obediencia no es sumisión, sino cuidado. Por ella comprendemos y nos comprendemos a partir de lo que nos arriba; no le sería posible a Ricœur hablar de obediencia si ésta no fuese una atención cuidadosa, exploratoria y prospectiva, dubitativa y crítica. Solo con la pausa de la paciencia, que es propia del cuidado, puede ser recibida la palabra que conmina; sin sumisión, abierto siempre a la contestación.

\section{VII.}

A modo de conclusión, podemos citar a Michel Foucault quien afirma que el "cuidado" -él se refiere a la epimeleia beautou griega- implica "una actitud general, una manera determinada de considerar las cosas, de estar en el mundo, de realizar acciones, de tener relaciones con el prójimo. La epimeleia beautou es una actitud: con respecto a sí mismo, con respecto a los otros, con respecto al mundo"55. Haciendo abstracción del

${ }^{54}$ Ibíd., p. 505.

${ }^{55}$ Foucault, Michel, Hérméneutique du sujet, Paris, Gallimard, Seuil, 2001, p. 28. Los análisis de Foucault se centran en un período bien determinado al que asigna el nombre de "espiritualidad", y que comprende desde la irrupción de Sócrates en la Atenas clásica hasta el siglo XVII, del que Descartes marcará un quiebre definitivo con la cuestión del "cuidado de sî"; por tanto, éste focaliza sus análisis en un período de tiempo, que aunque bien extenso es también bien determinado a autores, textos y prácticas que fueron variando a lo largo de la historia y tomando un sentido distinto y a veces hasta opuesto; sin embargo, me parece que la caracterización general que el autor hace de la epimeleia nos da elementos para identificar algunos rasgos constitutivos que pueden aportarnos una comprensión más global del cuidado, pudiendo también prescindir de los análisis históricos en 
fundamento histórico que tienen los análisis de Foucault sobre la epimeleia, quisiera tomar la indicación que hace el autor respecto del cuidado como "actitud", pues a mi parecer aporta claridad a nuestra descripción fenomenológica sobre la dimensión responsiva del cuidado.

En primer lugar, es posible concluir que el cuidado está lleno de intencionalidad, pues determina el modo cómo el ser humano está abierto a sí y al mundo, al mismo tiempo que es transitividad, pues finalmente el cuidado no sería tal si tan solo fuera un modo -por muy esencial que éste sea- de ser que tiene el sujeto para salir fuera de sus goznes; el cuidado supone, a partir de lo abierto en lo que nos define, todo un movimiento de acogida o recepción de lo otro; nos aporta el sentimiento de implicación; aquello que soy, aquello próximo o, incluso, lejano, me concierne de una u otra forma. Así, incluso si el cuidado es ciego a su propio movimiento intencional, posee, sin embargo, una lucidez bien particular: la de alumbrar, a través de un comportamiento de aproximación o de rodeo aquello como lo que nos concierne; si esto es así, habría que sostener también que el cuidado compromete una "crisis" del sujeto y de lo concernido. ¿En qué sentido? Del sujeto en cuanto se halla, de aquí en adelante, intervenido, interferido en su propio constituirse o, si se quiere, en el reconocimiento de sí por sí mismo. El sujeto que asume el cuidado de... porque se halla concernido por..., al mismo tiempo, se recibe en una tarea, en una conminación que es preciso saber "atender", inclusive si al asumirla no tenemos idea cómo lo haremos. Pienso, por ejemplo, en el caso de asumir la paternidad de nuestros hijos. Tener un hijo implica aceptar "hacerme cargo" de él, asumir el cuidado y los cuidados que le debo, lo que no significa de ningún modo que sepa cómo hacerlo -hay tal vez aquí una responsabilidad que asumimos como en vértigo-. De este modo, recibir y cuidar al otro puede significar un cambio de actitud que me pone delante de o respecto de, y me saca siempre de

los que se compromete Foucault (para un examen más detallado, cfr. Galzinga, Mario, "La vérité-événement", Critique, Paris, Minuit, 2009/10, pp. 860-871; Le Blanc, Guillaume, "L'invention de l'homme moderne. Une lecture de Michel Foucault". Philosophie, Paris, PUF, 2011, pp. 60-73 y Gros, Frédéric, Michel Foucault, Paris, PUF, 2010, pp. 91-123). 
mis goznes. El cuidado hace entrar en crisis al sujeto porque lo interfiere ofreciéndole una concernencia. Pero también aporta una crisis de lo "por cuidar". Pues, finalmente reconocer a alguien como aquello de lo que debo hacerme cargo supone también una actitud por la cual el objeto -en un amplio sentido- de nuestro cuidado no se deja reducir ni al modo de ser de un ente presente o subsistente, ni de un objeto manipulable $\mathrm{o}$ técnico, ni de un hecho o un dato. La actitud con la que confrontamos eso "por cuidar" lo manifiesta con un cariz distinto, pero al mismo tiempo lo interroga de otro modo que no es el habitual.

Lo interesante es que esta disponibilidad del cuidado comprende una verdadera conversión de la mirada que quiebra los modos habituales de dirigirnos hacia las cosas y atenderlas. De allí la posibilidad de su inquietud. ¿Por qué volvemos nuestra mirada hacia otra persona, hacia un interés distinto, hacia una actividad en la que buscamos comprometernos? Pero, y sobre todo, ¿cuáles son las razones para hacer de ese cambio de dirección una actitud en la que comprometernos? No solo se trata de un cambio de mirada, sino de una verdadera conversión, es decir, de un volverse hacia algo que no estaba previsto, que antes no resonaba, que no conminaba y que, seguramente, ni siquiera aparecía en el campo atencional como algo para ser enfocado.

Si el fenómeno está bien visto, habría que concluir momentáneamente que solo nos comprometemos en el cuidado una vez que algo ha irrumpido, estallado en nosotros o a nosotros. Conminación y acontecimiento son dos componentes propios del "ser de cuidado" que somos, pues parece que este segundo momento aporta al primero una lucidez que viene de un encuentro, de un arrebato, de un exceso que ordena, que mandata al sí-mismo a comprometerse en una serie de ejercicios, de prácticas que lo ponen en juego, vale decir que lo manifiestan, revelan o, si se prefiere, que le arrostran su propio ser que, antes de estar dado como un hecho, está presente como una tarea por ser realizada.

Toda nuestra empresa ha consistido, de este modo, en comprender al cuidado como un modo de ser propio del ser humano, una manera de ser responsivo ante la alteridad que constituye, adviene y 
descentra al sujeto. Las respuestas en las que nos comprometemos, por las que nos reconocemos responsables y atestiguamos como sujetos capaces de insertar nuestra acción en el mundo así como sujetos vulnerables y pacientes, no podrían ser tales sin fundarse en un cierto cuidado, el cuidado de las respuestas o la paciencia en la que éstas surgen y por la que somos enviados por senderos que se abren tan solo después del encuentro con la alteridad que nos interpela en nuestras capacidades.

El cuidado remite a la posibilidad que tiene el sujeto de hacerse cargo de sí mismo, de asumirse en una "responsabilidad" que puede extenderse más allá de sus límites al tomar forma ante la solicitud del mundo y del otro. Lo que significa que compromete al sujeto en sus respuestas. A lo que nos abre el responder, como un modo de ser propio del ser humano o del sí-mismo, es también a una filosofía de la implicación, de la concernencia, del compromiso y de la disponibilidad, recordándonos la estrecha relación entre la hermenéutica del sí-mismo y la fenomenología de la disponibilidad que Gabriel Marcel desplegó a lo largo de su obra, y que fue tan influyente en el pensamiento de Paul Ricœur ${ }^{56}$. Pero, por otro lado, una hermenéutica de la responsividad ha situado nuestra reflexión al interior de las filosofías de la apelación o interpelación ${ }^{57}$. En este sentido, el cuidado aporta una crítica del sujeto, en particular, del sujeto trascendental que la fenomenología husserliana ha erigido como paradigma de la subjetividad: ante un ego puro y desinteresado, es preciso subrayar la emergencia de un yo en acusativo, de un "heme aquí". En esto hemos seguido al joven Ricœur que, ya en un artículo de 1940 dedicado a la atención, rechazaba al sujeto trascendental husserliano para pensar más bien un sujeto con otro, implicado, concernido y de ningún modo neutro.

56 Begué, Marie-France, "La promesse et la fidélité : dialogue avec Gabriel Marcel", en Paul Rickur. La pensée en dialogue (sous la direction de Jérôme Porée et Gilbert Vincent), Rennes, PUR, 2010.

${ }^{57}$ Cfr. Rodríguez, Ramón (2008). "Apelación y subjetividad. Un escenario de la crítica del sujeto". $\Delta \alpha i \mu \omega v$. Revista de filosofía, suplemento 2, pp. 31-42 y Mena Patricio, "Homo capax". 
"El carácter interpelante del cuidado" pone en evidencia, precisamente, tal crítica al trascendentalismo fenomenológico en pos de un sujeto concernido y descentrado. De este modo, el sujeto de cuidado lo es en última instancia o, si se quiere, en segunda instancia, pues lo que es lo es responsivamente ante las múltiples interpelaciones a las que responde. Alguien llama, conmina y apela nuestras respuestas: saber escuchar, hacer silencio y obedecer son también otras tantas notas constitutivas de la lucidez del cuidado que ponen de manifiesto el carácter irruptor y apelante del "encuentro" abierto por o en la interpelación: una palabra, ciertamente; una palabra que al mismo tiempo es capaz de poner en suspenso por ejemplo la vida entendida en un sentido restringido y opuesto al de la existencia, capaz, también de abrinos al mundo del sentido y lo posible ${ }^{58}$. Lo que aquí está en juego es la relación compleja del binomio autonomía-obediencia. Pero, obediencia ante qué. Según Ricœur, ante el acontecimiento de palabra en la "escucha mutua, de hombre a hombre" 59 . Situar nuestro descripción eidética del cuidado en el ámbito de la mutualidad nos ha exigido interrogarnos por el modo cómo éste alumbra nuestra relación con los otros que nos solicitan, que nos interpelan, que a través del grito de un hijo o de la inteligencia de la palabra nos descentran de nuestros intereses y nos envían en nuestras respuestas hacia posibles inesperados. El acontecimiento del encuentro no solo estremece y desfonda nuestras pretensiones de auto-fundación, de autonomía y de transparencia, sino que nos requiere como responsables del sentido advenido y recibido.

Recibido: 06/2013. Aceptado: 09/2013

58 Cfr. Ricœur, P., “Autonomie et obéissance”, y Ricœur, P., "La Parole, instauratrice de liberté".

${ }^{59}$ Ricour, P., "La Parole, instauratrice de liberté", p. 500. 